University of Wollongong

Research Online

Faculty of Engineering - Papers (Archive)

Faculty of Engineering and Information

Sciences

2006

\title{
Magnetic field processing to enhance critical current densities of MgB2 superconductors
}

\author{
SX. Dou \\ University of Wollongong, shi@uow.edu.au \\ Wai Kong Yeoh \\ University of Wollongong \\ Olga V. Shcherbakova \\ University of Wollongong, olga@uow.edu.au \\ Josip Horvat \\ University of Wollongong, jhorvat@uow.edu.au \\ Jung Ho Kim \\ University of Wollongong, jhk@uow.edu.au
}

See next page for additional authors

Follow this and additional works at: https://ro.uow.edu.au/engpapers

Part of the Engineering Commons

https://ro.uow.edu.au/engpapers/2591

\section{Recommended Citation}

Dou, S X.; Yeoh, Wai Kong; Shcherbakova, Olga V.; Horvat, Josip; Kim, Jung Ho; Pan, Alexey V.; Wexler, David; Li, Yongqing; Li, W X.; Ren, Z M.; Munroe, Paul G.; and Cui, J Z.: Magnetic field processing to enhance critical current densities of MgB2 superconductors 2006, 202504-1-202504-3.

https://ro.uow.edu.au/engpapers/2591 


\section{Authors}

S X. Dou, Wai Kong Yeoh, Olga V. Shcherbakova, Josip Horvat, Jung Ho Kim, Alexey V. Pan, David Wexler, Yongqing Li, W X. Li, Z M. Ren, Paul G. Munroe, and J Z. Cui 


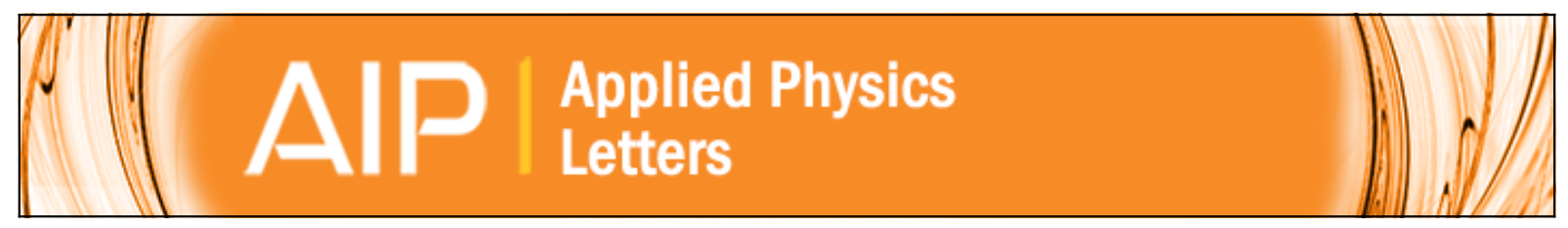

Magnetic field processing to enhance critical current densities of Mg B 2

\section{superconductors}

S. X. Dou, W. K. Yeoh, O. Shcherbakova, J. Horvat, J. H. Kim, A. V. Pan, D. Wexler, Y. Li, W. X. Li, Z. M. Ren, P. Munroe, and J. Z. Cui

Citation: Applied Physics Letters 89, 202504 (2006); doi: 10.1063/1.2388126

View online: http://dx.doi.org/10.1063/1.2388126

View Table of Contents: http://scitation.aip.org/content/aip/journal/apl/89/20?ver=pdfcov

Published by the AIP Publishing

\section{AlP Re-register for Table of Content Alerts}

\section{Create a profile. \\ Sign up today!}




\title{
Magnetic field processing to enhance critical current densities of $\mathrm{MgB}_{2}$ superconductors
}

\author{
S. X. Dou, ${ }^{\text {a) }}$ W. K. Yeoh, O. Shcherbakova, J. Horvat, J. H. Kim, A. V. Pan, and D. Wexler \\ Institute for Superconducting and Electronic Materials, University of Wollongong, Northfields Ave., \\ Wollongong, New South Wales 2522, Australia \\ Y. Li, W. X. Li, and Z. M. Ren \\ Department of Materials Science and Engineering, Shanghai University, Shanghai 200072, China \\ P. Munroe \\ Electron Microscope Unit, University of New South Wales, Sydney, New South Wales 2000, Australia
}

J. Z. Cui

Faculty of Engineering, Northeastern University, Shenyang 110004, China

(Received 24 January 2006; accepted 5 October 2006; published online 14 November 2006)

\begin{abstract}
A magnetic field of up to $12 \mathrm{~T}$ was applied during the sintering process of pure $\mathrm{MgB}_{2}$ and carbon nanotube $(\mathrm{CNT})$ doped $\mathrm{MgB}_{2}$ wires. The authors have demonstrated that magnetic field processing results in grain refinement, homogeneity, and enhancement in $J_{c}(H)$ and $H_{\text {irr. }}$. The extent of improvement in $J_{c}$ increases with increasing field. The $J_{c}$ for a $10 \mathrm{~T}$ field processed CNT doped sample increases by a factor of 3 at $10 \mathrm{~K}$ and $8 \mathrm{~T}$ and at $20 \mathrm{~K}$ and $5 \mathrm{~T}$, respectively. $H_{\text {irr }}$ for the $10 \mathrm{~T}$ field processed CNT doped sample reached $9 \mathrm{~T}$ at $20 \mathrm{~K}$, which exceeded the best value of $\mathrm{SiC}$ doped $\mathrm{MgB}_{2}$ at $20 \mathrm{~K}$. Magnetic field processing reduces the resistivity in $\mathrm{CNT}$ doped $\mathrm{MgB}_{2}$, straightens the entangled CNTs, and improves the adherence between CNTs and the $\mathrm{MgB}_{2}$ matrix. (C) 2006 American Institute of Physics. [DOI: 10.1063/1.2388126]
\end{abstract}

$\mathrm{MgB}_{2}$ superconductor has made a significant impact on superconductivity research and development since its discovery. ${ }^{1}$ Chemical doping has been used to enhance the critical current density $J_{c}$ and the upper critical field $H_{c 2}{ }^{2-5}$ Carbon and silicon carbide doping resulted in a significant increase of in-field $J_{c}$ and $H_{c 2}$, and these records still stand for $\mathrm{MgB}_{2} \cdot{ }^{5-7}$ To further advance the development of $\mathrm{MgB}_{2}$ for applications we report a method of combining the magnetic field processing and carbon nanotube (CNT) doping. Magnetic field processing technology has proved to be a powerful tool to produce aligned carbon nanotubes (CNTs) in composites and macroscopic membranes ${ }^{8,9}$ and control the phase transformation and behavior of the melts during condensation processes, resulting in major improvements in material properties. ${ }^{10,11}$ Magnetic field processing has also been used to achieve the desired texture and improved $J_{c}$ performance in high temperature superconductors. ${ }^{12-15}$ In processing of $\mathrm{MgB}_{2}$ bulk and wires the reaction in situ technique in combination with the powder-in-tube method has been used to produce the wires with the best field performance. ${ }^{16}$ In the in situ reaction process, $\mathrm{Mg}$ melts before the $\mathrm{MgB}_{2}$ formation by solid state reaction, provided that the heating rate is high enough. The presence of a liquid phase provides a window of opportunity for applying a magnetic field processing technique to achieve crystalline refinement, homogeneous distribution of additives and inclusions, and possible alignment of both matrix materials and additives.

In this work, a standard powder-in-tube method was used for Fe clad $\mathrm{MgB}_{2}$ wire. ${ }^{17}$ Powders of magnesium (99\%) and amorphous boron (99\%) were well mixed with 0 and 10 wt $\%$ of multiwall CNTs [outside diameter (o.d.) of

a) Author to whom correspondence should be addressed; electronic mail: shi_dou@uow.edu.au
$20 \mathrm{~nm}$ and length of $0.5-2 \mu \mathrm{m}]$ and thoroughly ground. The Fe tube had an o.d. of $10 \mathrm{~mm}$ and a wall thickness of $1 \mathrm{~mm}$ and was $10 \mathrm{~cm}$ long with one end of the tube sealed. The mixed powder was packed into the tube, and the remaining end was blocked using an aluminum bar. The composite was drawn to a $1.4 \mathrm{~mm}$ diameter wire. Several short samples $2-3 \mathrm{~cm}$ in length were cut from the same wire. Some wires were rolled into tapes for study of anisotropy. These pieces were sealed in $\mathrm{Fe}$ tubes, then sintered in a tube furnace at $800-900{ }^{\circ} \mathrm{C}$ for $30 \mathrm{~min}$ in magnetic fields up to $12 \mathrm{~T}\left(H_{a}\right)$, with a high heating rate of $20^{\circ} \mathrm{C} / \mathrm{min}$, and finally furnace cooled to room temperature. The processing field was applied parallel or perpendicular to the wire axis before the temperature was ramped up. The same processing conditions were used to treat the wire samples with field on and field off for comparison.

The magnetization of cores taken from the wires was measured at 5 and $20 \mathrm{~K}$ using a Quantum Design Physical Property Measurement System with a magnetic field sweep rate of $50 \mathrm{Oe} / \mathrm{s}$ and amplitude up to $9 \mathrm{~T}$. Since there is a large sample size effect on the magnetic $J_{c}$ for $\mathrm{MgB}_{2}$ fabricated by the reaction in situ process, all the samples for

TABLE I. Transition temperature, resistivity, and lattice parameters for undoped $\mathrm{MgB}_{2}$ and $\mathrm{CNT}$ doped $\mathrm{MgB}_{2}$ wires with and without field processing.

\begin{tabular}{ccccc}
\hline \hline Sample & $T_{c}(\mathrm{~K})$ & $\rho_{40 \mathrm{~K}}(\mu \Omega \mathrm{cm})$ & $\rho_{300 \mathrm{~K}}(\mu \Omega \mathrm{cm})$ & $\mathrm{RRR}$ \\
\hline $\mathrm{MgB}_{2}(0 \mathrm{~T})$ & 37.7 & 28.0 & 63.0 & 2.2 \\
$\mathrm{MgB}_{2}(5 \mathrm{~T})$ & 37.7 & 23.5 & 58.0 & 2.4 \\
$\mathrm{CNT}(0 \mathrm{~T})$ & 35.6 & 50.8 & 81.0 & 1.6 \\
$\mathrm{CNT}(10 \mathrm{~T})$ & 36.7 & 34.3 & 63.0 & 1.9 \\
$\mathrm{CNT}(0 \mathrm{~T})$ & 35.4 & 61.6 & 96.6 & 1.6 \\
$\mathrm{CNT}(12 \mathrm{~T})$ & 36.1 & 43.5 & 75.6 & 1.7 \\
\hline \hline
\end{tabular}




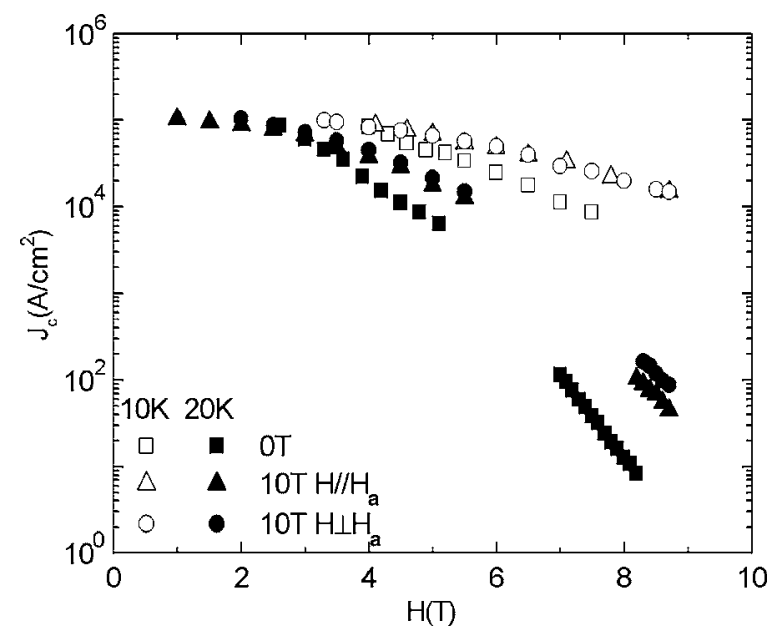

FIG. 1. $J_{c}$ vs $H$ for $10 \% \mathrm{CNT}$ doped $\mathrm{MgB}_{2}$ tapes, processed at $900{ }^{\circ} \mathrm{C}$ for 30 min without magnetic field and with a $10 \mathrm{~T}$ field, respectively.

measurement were made to the same size for comparison. The magnetic $J_{c}$ was derived from the height of the magnetization loop using the critical state model. Samples were measured with the field $H$ applied perpendicular and parallel to the wire axis. The transport $J_{c}$ was measured with the four-probe method, using a pulsed current source for critical currents down to about $70 \mathrm{~A}$. In the high field region, which was characterized by critical currents lower than $1 \mathrm{~A}$, a dc source was used to measure the transport $J_{c}$.

Table I lists the basic data for the undoped $\mathrm{MgB}_{2}$ and 10 wt $\%$ CNT doped $\mathrm{MgB}_{2}$ wires processed with and without magnetic field. The $T_{c}$ for the undoped $\mathrm{MgB}_{2}$ remained unchanged with field processing, while there is a small increase in the $T_{c}$ for the two pairs of CNT doped samples which were processed without applied field and with 10 and $12 \mathrm{~T}$ fields, respectively. The resistivity was reduced by 20\%-30\% with field processing for both the undoped and CNT doped samples. Accordingly, there is an increase in the residual resistivity ratio (RRR) value for both samples. There is no noticeable change in lattice parameters for both the undoped and CNT doped samples with field processing. The interaction between magnetic field and materials will generate magnetization force, which can act as pulling force for magnetic and paramagnetic materials or repulsing force for diamagnetic materials. The magnetization force will also tend to rotate the crystals to align with the field direction if there is anisotropy in the overall magnetic susceptibility. As a result of these forces the magnetic processing has several beneficial effects, including improved interaction between components, reduced size of crystallites, homogenization, reduction of impurities, and alignment of parent or additive materials. The observed reduction in resistivity for both the undoped and CNT doped samples may be attributable to the improvement in convection and diffusion of components in the applied magnetic fields during $\mathrm{Mg}$ melting. There are no data on the magnetic property at high temperatures for $\mathrm{Mg}$, $\mathrm{B}$, and CNT. At room temperatures, $\mathrm{B}$ and $\mathrm{MgB}_{2}$ were found to be diamagnetic, ${ }^{18,19}$ while CNT could be diamagnetic or paramagnetic depending on the helical structure, magnetic field, and orientation. ${ }^{20-22}$ As many metals, $\mathrm{Mg}$ could become paramagnetic in strong fields. It is evident that the magnetization force on $\mathrm{B}, \mathrm{CNT}$, and $\mathrm{Mg}$ will be different. It is the difference in magnetization force that will increase the migration among these components and hence improve the

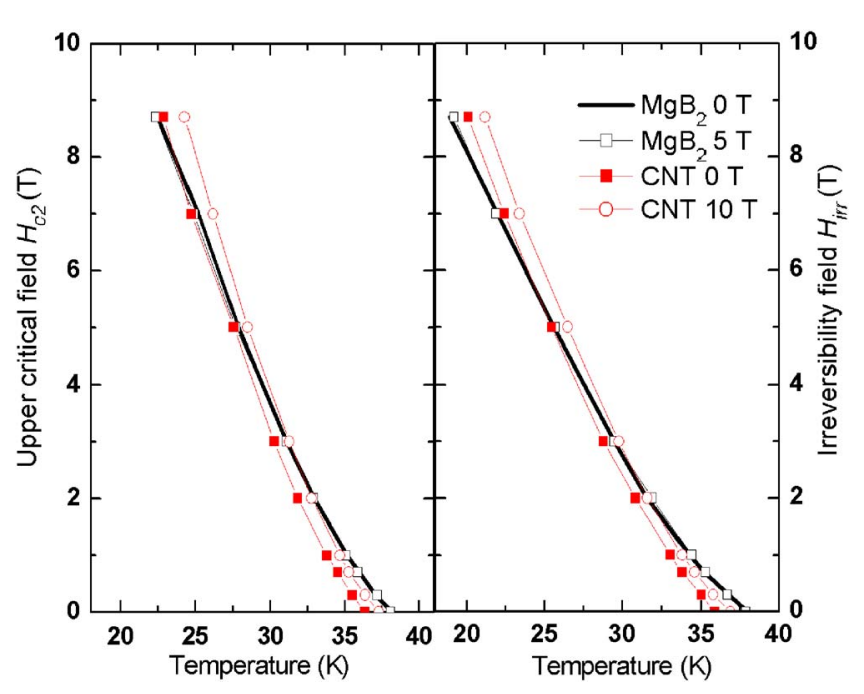

FIG. 2. (Color online) Upper critical field $H_{c 2}$ (a) and irreversibility field $H_{\text {irr }}$ (b) as a function of temperature for undoped and $10 \% \mathrm{CNT}$ doped $\mathrm{MgB}_{2}$ wires.

interaction between them, which, in turn, enhance the crystallinity and grain connectivity.

Figure 1 shows the transport $J_{c}(H)$ curves for the $10 \%$ CNT doped $\mathrm{MgB}_{2}$ tape samples processed without field and with a $10 \mathrm{~T}$ field at $900{ }^{\circ} \mathrm{C}$. A pronounced $J_{c}$ enhancement was observed in the entire field region at both 10 and $20 \mathrm{~K}$ for the field processed sample. For the CNT doped sample, the resistivity $\rho_{40 \mathrm{~K}}$ was reduced by $30 \%$ for the field processed sample, and there was a moderate increase in $T_{c}$ due to the field processing (Table I). The XRD data indicate that there is no change in the lattice parameters upon field processing for both the undoped and CNT doped samples. Thus, the improvement in the resistivity may be attributable to the improved grain connectivity and the connectivity between CNTs and $\mathrm{MgB}_{2}$ grains. The extent of the enhancement in $J_{c}$ due to the field processing increases with increasing measurement field $H$. For example, the $J_{c}$ for a $10 \mathrm{~T}$ field processed CNT doped sample increases by a factor of 3 at $10 \mathrm{~K}$ and $8 \mathrm{~T}$ and at $20 \mathrm{~K}$ and $5 \mathrm{~T}$, respectively. It is particularly worth noting that the irreversibility field $\left(H_{\text {irr }}\right)$ for the field processed sample reached $9 \mathrm{~T}$, which exceeded the record value for the $\mathrm{SiC}$ doped $\mathrm{MgB}_{2}$ at $20 \mathrm{~K}^{5}$ The $J_{c}$ for the CNT doped sample shows a small anisotropy when the measurement field $H$ is applied perpendicular $\left(H \perp H_{a}\right)$ and parallel to the processing field $H_{a}\left(H / / \mathrm{H}_{a}\right)$. As the $\mathrm{MgB}_{2}$ crystals are not aligned in the magnetic field, the anisotropy in the CNT doped $\mathrm{MgB}_{2}$ may be attributable to some extent to CNT alignment in the field. Figure 2 shows the upper critical field $H_{c 2}$ and irreversibility field $H_{\text {irr }}$ versus temperature $T$ for the undoped and CNT doped samples processed with field and without field. The field processing showed no effect on $H_{c 2}$ and $H_{\text {irr }}$ for the undoped sample but a small improvement for the CNT doped sample within the limited field up to $9 \mathrm{~T}$.

As reported in previous work, the added CNTs were entangled in the $\mathrm{MgB}_{2}$ matrix for the non-field-processed sample and appeared as mainly bare CNTs that were not well bonded to the $\mathrm{MgB}_{2}$ matrix. ${ }^{8}$ In contrast, all the CNTs in the magnetic field processed sample are straightened and embedded in the $\mathrm{MgB}_{2}$ matrix as shown in Fig. 3(a). Figure 3(b) shows a focused ion beam (FIB) assisted SEM for the CNT doped $\mathrm{MgB}_{2}$ processed with a $5 \mathrm{~T}$ pulsed magnetic field ap- 


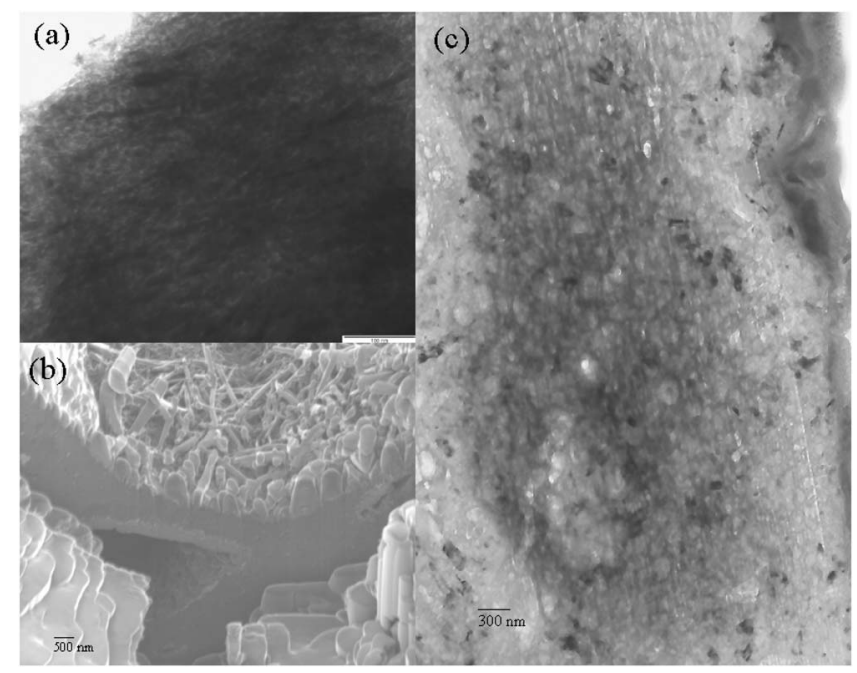

FIG. 3. Transmission electron micrographs for CNT doped $\mathrm{MgB}_{2}$ processed with a $10 \mathrm{~T}$ field (a), FIB-SEM micrograph of straight $\mathrm{MgB}_{2}$ whiskers formed on the CNTs in $5 \mathrm{~T}$ field (b), and TEM image of aligned CNTs embedded in the $\mathrm{MgB}_{2}$ matrix in $5 \mathrm{~T}$ field (c).

plied along the wire axis direction. The magnetic field processing converts the CNT agglomerates to whiskers with lengths of about $2-5 \mu \mathrm{m}$ and diameters of $200-400 \mathrm{~nm}$, which is ten times that for CNTs. These whiskers are formed under magnetic field with CNTs as nucleation centers for the $\mathrm{MgB}_{2}$ growth in the area of CNT agglomerates. These whiskers are mostly straight with good contact among them. These $\mathrm{MgB}_{2}$ whiskers would be good conductors, accounting for the enhancement of $J_{c}$ in the low field region. Figure 3(c) is a transmission electron microscopy (TEM) image showing a number of aligned and straight CNTs embedded in the $\mathrm{MgB}_{2}$. The aligned CNTs will improve the grain connectivity and act as efficient flux pinning sites. This observation is consistent with the observed strong anisotropy in $J_{c}(H)$ for field processed CNT doped $\mathrm{MgB}_{2}$. Such anisotropy is lacking for pure $\mathrm{MgB}_{2}$. Ajiki and Ando, ${ }^{20} \mathrm{Lu},{ }^{21}$ and Ramirez et $a .^{22}$ found that the susceptibility $\chi$ of CNTs is large enough for them to be aligned in certain magnetic fields. The melting of $\mathrm{Mg}$ could create some liquid environment for the rotating force to align CNTs in field. However, there is substantive solid B particles in the composite. Thus, the extent of CNT movement due to magnetization force will be very limited.

The advantages of the magnetic field processing include the provision of a unique window of opportunity to control the microstructure and the behavior of various additives that have a response to magnetic field. We can extend the conventional materials processing variables of pressure, composition, and temperature, $f(P, C, T)$, to include field $(H)$ and magnetization $(M)$ of the matrix and additives,
$f(P, C, T, H, M)$. We can manipulate various combinations of the parameters such as field strength, processing temperature and time, and the properties of additives to achieve an optimal enhancement in $J_{c}(H)$. As the formation of $\mathrm{MgB}_{2}$ in the reaction in situ technique is a rapid process, magnetic field processing can be used in large-scale production.

This work was supported by the Australian Research Council, Hyper Tech Research Inc, OH, U.S.A., and Alphatech International Ltd., N.Z. The authors thank Dr. X. L. Wang, Dr. A. Pan, Dr. T. Silver, and M. Tomsic for helpful comments. One of the authors (W.K.Y.) received an Australia-Asia Award funded by the Australian Government. Two of the authors (Z.M.R. and Y.L.) would like to thank the Natural Science Foundation of China for their support.

${ }^{1}$ J. Nagamatsu, N. Nakagawa, T. Muranaka, Y. Zenitani, and J. Akimitsu, Nature (London) 410, 63 (2001).

${ }^{2}$ S. X. Dou, S. Soltanian, J. Horvat, X. L. Wang, P. Munroe, S. H. Zhou, M. Ionescu, H. K. Liu, and M. Tomsic, Appl. Phys. Lett. 81, 3419 (2002).

${ }^{3}$ R. H. T. Wilke, S. L. Bud'ko, P. C. Canfield, D. K. Finnemore, R. J. Suplinskas, and S. T. Hannahs, Phys. Rev. Lett. 92, 217003 (2004).

${ }^{4}$ S. X. Dou, W. K. Yeoh, J. Horvat, and M. Ionescu, Appl. Phys. Lett. 83, 4996 (2003).

${ }^{5}$ H. Kumakura, H. Kitaguchi, A. Matsumoto, and H. Hatakeyama, Appl. Phys. Lett. 84, 3669 (2004).

${ }^{6}$ S. X. Dou, V. Braccini, S. Soltanian, R. Klie, Y. Zhu, S. Li, X. L. Wang, and D. Larbalestier, J. Appl. Phys. 96, 7549 (2004).

${ }^{7}$ M. D. Sumption, M. Bhatia, M. Rindfleisch, M. Tomsic, and E. W. Collings, Appl. Phys. Lett. 86, 102501 (2005).

${ }^{8}$ E. S. Choi, J. S. Brooks, D. L. Eaton, M. S. Al-Haik, M. Y. Hussaini, H. Garmestani, D. Li, and K. Dahmen, J. Appl. Phys. 94, 6034 (2003).

${ }^{9}$ M. J. Casavant, D. A. Walters, J. J. Schmidt, and R. E. Smalley, J. Appl. Phys. 93, 2153 (2003).

${ }^{10}$ G. M. Ludtka, R. A. Jaramillo, R. A. Kisner, D. M. Nicholson, J. B. Wilgen, G. Mackiewicz-Ludtka, and P. N. Kalu, Scr. Mater. 51, 171 (2004).

${ }^{11}$ Y. Liu, J. Zhang, G. Jia, X. Zhang, Z. Ren, X. Li, C. Jing, S. Cao, and K. Deng, Phys. Rev. B 70, 184424 (2004).

${ }^{12}$ P. de Rango, M. Lees, P. Lejay, A. Sulpice, R. Tournier, M. Ingold, P. Germi, and M. Pernet, Nature (London) 349, 770 (1991).

${ }^{13}$ J. G. Noudem, J. Beille, D. Bourgault, D. Chateigner, and R. Tournier, Physica C 264, 325 (1996).

${ }^{14}$ X. Y. Lu, A. Nagata, K. Watanabe, T. Nojima, D. Kamio, K. Sugawara, and S. Kamada, IEEE Trans. Appl. Supercond. 11, 3553 (2001).

${ }^{15}$ H. B. Liu, P. J. Ferreira, J. B. Vander Sande, and A. Otto, Physica C 316, 234 (1999).

${ }^{16}$ S. X. Dou, J. Horvat, S. Soltanian, X. L. Wang, M. J. Qin, S. H. Zhou, H. K. Liu, and P. G. Munroe, IEEE Trans. Appl. Supercond. 13, 3199 (2003).

${ }^{17}$ S. Soltanian, X. L. Wang, I. Kusevic, E. Babic, A. H. Li, H. K. Liu, E. W. Collings, and S. X. Dou, Physica C 361, 84 (2001).

${ }^{18}$ Y. Wang, T. Plackowski, and A. Junod, Physica C 355, 179 (2001).

${ }^{19}$ S. Reith, G. Leitus, and I. Felner, J. Supercond. 15, 109 (2002).

${ }^{20} \mathrm{H}$. Ajiki and T. Ando, J. Phys. Soc. Jpn. 62, 2470 (1993).

${ }^{21}$ J. P. Lu, Phys. Rev. Lett. 74, 1123 (1995).

${ }^{22}$ A. P. Ramirez, R. C. Haddon, O. Zhou, R. M. Fleming, J. Zhang, S. M. McClure, and R. E. Smalley, Science 265, 84 (1994). 